\title{
Change in Family Structure in the Modern Times
}

\author{
Himani Bhasin ${ }^{1 *}$
}

Keywords: Family Structure, Modern Times

In India, the land of culture and unity, culture and unity are well manifested in the structure of society, indeed in the smaller unit of a society i.e. family.

A family is a set of human beings related to each other in a non-professional manner, giving rise to a concrete cohesion within the family. Love, care, and affection are the most prominent human values, which are responsible for maintaining these bonds of relationships within a family.

Typically, a nuclear family may be conceived as a unit consisting of a couple, children, and grandparents, and pets. In India however, there exists a special kind of family structure that really is quite vivid in the way it manages to handle and keep intact the human relations. This special kind of family structure is Joint Family System. A joint family is a collection of more than one, nuclear families that are interconnected by blood relations or marital relations. All the members, regardless of which particular nuclear family (within that joint family) they belong to, live together and share happiness, grief, and virtually every kind of problem and joy together. The joint family in itself simulates a typical view of our multi-cultural, multi-lingual, yet tightly intertwined Indian society. Indian president replies to a question related to spiritual strengths of India as:

“One of our strengths is our joint family system. In this system a problem is no problem. In a nuclear family a problem can destroy a family. We have a number of religions. I find that religions are like orchards, but they need to be linked. Every religion preaches compassion and love. If we can transform religion into spiritual Forces then we have arrived. By 2020 we should be a prosperous and happy nation without losing our civilization heritage....”

\section{Family Orientation}

The family is the basic unit of society. Families exist in all sizes and configurations and are essential to the health and survival of the individual members and to society as a whole.

\footnotetext{
${ }^{1}$ HR Professional, Pepsi Franchisee, Varun Beverages Limited, Gurgaon, New Delhi, India *Responding Author

(C) 2016, H Bhasin; licensee IJIP. This is an Open Access Research distributed under the terms of the Creative Commons Attribution License (http://creativecommons.org/licenses/by/2.0), which permits unrestricted use, distribution, and reproduction in any Medium, provided the original work is properly cited.
} 


\section{Change in Family Structure in the Modern Times}

As the primary group for the individual, the family serves as a buffer between the needs of the individual and the demands and expectations of society.

The family is a unity of interacting persons related by ties of marriage, birth or adoption, whose central purpose is to create and maintain a common culture which promotes the physical, mental, emotional and social development of each of its members

-Duval, 1971

In today's society, the family as composed of two or more people who are emotionally involved with each other and live in close geographical proximity.

Friedman

The family provides a set of functions important to the needs of the individual members and to society as a whole. The family provides the individual with the necessary environment for development and interactions; it also provides new and socialized members for society.

\section{Four Major Functions of a Family: (Friedman, 1981)}

(i) Physical Function - carried out by providing a safe, comfortable environment necessary to growth, development and rest/recuperation.

(ii) Economic Function - provide financial aid for members, as well as, meeting monetary needs of society.

(iii) Reproductive Function - it is met by the birth of children.

(iv) Socialization Function - this is of major importance and includes teaching; transmitting beliefs, values, attitudes and coping mechanisms; providing feedback and guiding problem - solving.

In most societies FAMILY is the principal institution for the socialization of children.

A family group consisting of a father, mother and their children is called a nuclear family. This term can be contrasted with an extended family.

\section{Types of Family}

A "conjugal" family includes only the husband, the wife, and unmarried children who are not of age. The most common form of this family is regularly referred to in sociology as a nuclear family.

A "consanguinal" family consists of a parent and his or her children, and other people.

A "matrifocal" family consists of a mother and her children. Generally, the children are mother's biological offspring. The different types of families occur in a wide variety of settings, and their specific functions and meanings depend largely on their relationship to other social institutions. The term "nuclear family" is commonly used, especially in North America and Europe, to refer to conjugal families.

(C) The International Journal of Indian Psychology, ISSN 2348-5396 (e) | ISSN: 2349-3429 (p) | 125 


\section{Change in Family Structure in the Modern Times}

The term "extended family" is also common, especially in North America and Europe. It serves as a synonym of "consanguinal family".

\section{Extended Family}

A Hindu Joint Family or Joint Family is an extended family arrangement prevalent among Hindus of the Indian subcontinent, consisting of many generations living under the same roof. The joint family status being the result of birth, possession of joint cord that knits the members of the family together is not property but the relationship.

The family is headed by a patriarch, usually the oldest male called "Karta", who makes decisions on economic and social matters on behalf of the entire family. The patriarch's wife generally exerts control over the kitchen, child rearing and minor religious practices. Family ties are given more importance than marital ties. The arrangement provides a kind of social security in a familial atmosphere.

Six key aspects of a joint family are:

Head of the family (Karta) takes all decision regarding financial and economical aspects of family.

All members live under one roof.

Share the same kitchen.

Three generations living together (though often two or more brothers live together, or father and son live together or all the descendants of male live together).

Income and expenditure in a common pool- property held together.

A common place of worship.

All decisions are made by the male head of the family- patrilineal, patriarchal.

No division of property until the death of the Karta (head of family or older male person).

\section{Nuclear Family}

A nuclear family is defined as a family group consisting of a father and mother and their children, all exclusively sharing living quarters.

This family is in contrast to the smaller single-parent family, and to the larger extended family. The concept of the nuclear family was first noticed in Western Europe in the 17th century. With the emergence of proto-industrialization and early capitalism, the nuclear family became a financially viable social unit.

The concept that a narrowly defined nuclear family is central to stability in modern society has been promoted by modern social conservatives in the United States, and has been challenged as historically and sociologically inadequate to describe the complexity of actual family relations and this concept has been widely accepted in India also.

(C) The International Journal of Indian Psychology, ISSN 2348-5396 (e) | ISSN: 2349-3429 (p) | 126 


\section{Change in Family Structure in the Modern Times}

\section{Aims and Objectives}

(i) To know the main reason in the increase of nuclear families or decrease in joint families.

(ii) To investigate the relationship of family structure and social values as they relate to family structure in contemporary Indian society.

(iii)The broad objective of the study is to know why "Youth prefer nuclear family most as compare to joint family".

(iv) To know the impact of western culture on the Indian youth today and change in preference of youth for family.

\section{LITERATURE REVIEW}

\section{Nuclear Family vs. Joint Family}

According to ChitraNair (2009)72\% city women prefer nuclear families and in a debate of Nuclear Family vs. Joint Family is explained that a Survey is carried by a famous matrimonial portal to find out the Preference of youth for Nuclear family or Join family and it appears that most of working women (72\%) want to be live in a nuclear family. The woman, who holds a well-paying job, wanted to live in a separate house "to avoid complications later". The young techie's opinion perhaps reflects a growing trend among city women. The survey carried out by a popular matrimonial portal claims to reveal changing attitudes among city youth towards various aspects of marriage. And in some matters, it appears, the fairer sex may be more open to change. According to the survey, for instance, almost $72 \%$ of Pune women prefer to live in a nuclear family, as opposed to just $50 \%$ men who favor the idea. The survey also highlights that questions like caste and horoscope matches are also losing importance among the city's youth. The survey also asked respondents how important it was for them to know their partner before marriage. A whopping $90 \%$ of female respondents from the city said it was extremely important, as opposed to some $79 \%$ men who said the same.

According to Anand Singh (2008) attitudes towards nuclear, joint and extended family living arrangements among middle-class people of Indian origin in Durban, South Africa. It takes the view that joint and extended family arrangements within this segment are still as popular as the growing western notion of nuclear families. The purposes of this article, is defined as an expression of preference for a particular type of living arrangement that could be one of three types, viz. nuclear, joint or extended family. Nuclear families are seen in this article as constituting two-generation households that are made up of parents and their biological children. Joint and extended family structures are viewed as being two distinct types of structures, but made up of individuals who are linked together by marriage and by their biological offspring. While joint and extended family structures among Indians are generally patrilineal and multifocal, an extended family differs from a joint family in that it is usually a three generation structure made up of genealogically related kin comprising of grandparents, parents and grandchildren, and sometimes a fourth generation, when it is does exist. A joint family, on the 


\section{Change in Family Structure in the Modern Times}

other hand, is usually made up of two married brothers and their families living in one property, without a third generation.

According to a debate conducted in Punjab University, the family as a unit is in its transition stage is an understatement but that many facets of it are either understudied or have remained untouched by the researchers was highlighted at the inaugural day of the 3-day seminar on" Family in contemporary India: Changes and challenges," which began in the Punjab University on Thursday. The seminar is jointly organized by the department of sociology, PU and the department of social security, development of women and children, Punjab at ICSSR complex, PU. In his inaugural address, Prof KL Sharma, vice chancellor of Rajasthan University, highlighted the importance of relationship between the siblings in the nuclear families apart from the numerous tensions between the husband and wife and parents and children that are confronted by the nuclear families in these times. Bringing out the futility of the shallow studies done on the vast subject of families in India, eminent expert on family studies Prof AM Shah, while delivering his key note address said, "It is futile to talk in terms of nuclear versus joint families, which is only an academic construction to understand Indian family. We must get out of this framework in order to grapple with the contemporary family composition." According to him, this entire talk of nuclear versus joint family has an upper class urban approach, as the dichotomy does not lie in all strata of society in the country. "Several decades ago, the tribes in central India used to set up a separate house for the newly-wed couple, which in a way is happening with the urban India which we categorize as nuclear family. But now, in the same tribes in central India, their earlier concept of a separate house for their son and daughter in law is vanishing as they are staying together as a joint family. So the argument that nuclear families are increasing and joint families are vanishing does not hold true for all sections of society," he said and also underlined the need to grasp the inter-household familial relationships without looking for spatial boundaries. Dean of Arts faculty, PU, Prof SL Sharma highlighted the role of sociology in debunking common sense assumptions concerning family forms in India. "Family ties must be placed in the context of globalization, changed working patterns of members, biotechnological changes and the increased level of militancy and terrorism," he said. Several sociologists from various universities presented papers in the subsequent technical sessions later in the seminar.

\section{Preference of Youth on Family Structure}

According to Choodie Shivaram, Bangalore, (2009), Joint Family at risk individualism has brought India's traditional family to the brink of extinction. Moreover if current trends continue, the turn of the 21st century may witness the extinction of one of society's most ancient and influential establishments, the joint family. In India, the joint family is a sacred institution deeply rooted in Hindu heritage. It has been heralded as the cultural strong hold that has borne Sanatana Dharma intact through India's inimical dominations. Lately, its prestige has plummeted. Though extended families exist in most parts of rural India and some cities, joint families are harder and harder to find. 


\section{Change in Family Structure in the Modern Times}

Indian families in are the most likely to be a success story in the joint family scenario, and hence are an example to the whole world on the way of life and happiness and unity in the Joint Families of India!

The family is a complex and dynamic institution in India and for many decades, several studies were carried out to understand this complexity. Some of the studies in the past have put forth the proposition of the existence of a joint family in the traditional Indian society (Mandelbaum, 1959). Most of the micro level studies have stated that the joint family in India is one of the common features among the higher castes (Gough, 1956; Kapadia, 1956; Cohn, 1961; Madan, 1965; Kolenda, 1968; Caldwell et. al, 1988; Shah, 1968, 1996; Srivastava and Nauriyal, 1993).Nimkoff (1959) has found that in India the joint family system is traditionally most common among the elite, the higher castes and those with more property. A preference for a joint family is demonstrated clearly in a variety of studies by urban and rural people, across caste and class (Ames, 1969; Conklin, 1976a \& b, 1988; Khatri, 1975). A district wise analysis of selected states in India by Kolenda and Haddon (1987) revealed that high joint family districts had more Hindus and substantially fewer Christians than the low joint family districts. In a study conducted in Karnataka, Caldwell et.al. (1984) showed that, the joint families are more common among those households which owned agricultural land etc.

According to Roger Marshall, Peter Alan Reday (2007) Internet-enabled youth has empowered family decisions \& the relationship between knowledge and power appears to be assumptive in marketing; the study reported here attempts to justify this assumption the study is set in a family decision context. The research divides families according to the domain-specific internet use of sons, and then the analysts inspect family decision-power patterns for a range of products. Analysis is by factor analysis in the first instance, followed by ANOVA to test the research hypotheses. Academics need to adjust their existing beliefs about family decisions; given the impact technology is having on

knowledge patterns. The concept that knowledge leads to power is not original, but the application of the idea to consider the structure of group decisions in a family context is. Most observers accept that the youth market is large and growing in its own right. It also seems possible, though, that many young consumers will have even more importance than previously considered because of their increasing influence within their family group.

\section{Effect of Western Culture on Indian Family Structure}

According to Deepa Mehta (2009), western impact on our Indian culture is felt more and more these days. The impact of western companies and their corporate culture has laid a heavy impact on the youth today. But needless to say our culture is one of the oldest and hence it is stable and nothing can really endanger it. Still a new form of living called nuclear families is on the increase. What is a nuclear family and how has it impacted our traditional family set up? Young couples after marriage decides to live independently away from the joint family setup. The reason for this choice is to be free and have increased privacy. It is very disheartening to see 


\section{Change in Family Structure in the Modern Times}

aged parents living alone waiting for their kids and grand children every weekend or during the holidays. Even that is not guaranteed because of lack of holidays in the respective offices of their son and daughter in law. What can be more disturbing when you have to celebrate birth days and festivals without your kids? The kids are looked after by paid maids and the so is the cooking and other domestic choirs. The head of the family is busy making money and the woman of the house also has a career or is busy socializing. The condition of the kids are the most pathetic as they while away their time before televisions and computers. But then do they get the privacy and the freedom assured in a nuclear setup. Well, where is the time for privacy when you are toiling day and night with little time at home to spend with the own kids. This defiantly brings more selfishness and one become less aware and sensitive of others. Whereas in joint families the man and the woman can continue their careers without worry of kids as the elders of the house take care of them. The kids grow in a loving and caring atmosphere around grandparents, nieces and nephews. The resources are shared and so it is benefits. Many parents feel the kids are spoiled by grandparents. The elders might pamper the kids but then they will not in any way stand in between the kids overall growth or studies. Joint family can also gives more support to carrier oriented parents by extending their love to kids. Parent need not to worry lot about the well being of their kids. In case of any incident or tragedy family members are the one who can stand beside you to give you the much required strength.

\section{Views of Youth on Indian Family Structure}

According to me as per the researches and supportive facts collected, it is found that there has been a dramatic change in the Indian family structure.

Since several decades there has been a sharp rise in the population of young couples preferring and living in a nuclear family.

Though Joint families have many advantages for any couple in terms of financial and social level, it is now felt essential to have privacy in various matters which only a nuclear family can provide.

Furthermore many other advantages such as child development, financial independence and freedom to make decisions are most beneficial to a young couple.

In India, there has been a rapid change in the family structure of the society. According to recent survey it has been found out that 1 in 5 Indian families (21\%)are third-generation joint families. Therefore, 4 in 5 (at most 75\%) families are nuclear.

As the youth has become more confident in taking decisions about their career choices, food, and lifestyle and also about living in a family. 


\section{Change in Family Structure in the Modern Times}

According to the results of the investigation, the main reason for the increase in nuclear family and joint family has been a need for a financially independent, socially organized and self-reliant family.

\section{DISCUSSIONS}

\section{Scope of study}

1. To know how fast the pattern of joint family is changing.

2. To see the rate of change in the preference of the youth for family.

3. How Western culture affect our and our family life.

4. Is it affecting the youth in negative or positive way.

\section{Setting-up of the hypothesis}

- $\quad$ The youth preference for nuclear family is increasing day by day

- The youth preference for joint family is not increasing, it is decreasing day by day

\section{Does The Youth Prefer A Nuclear Family?}

As the youth has become more confident in taking decisions about their career choices, food, and lifestyle and also about living in a family.

Moreover the drawbacks of the joint family also serve as a reason for the youth to switch over or choose living in a nuclear family. The drawback of joint family is that people don't get freedom and privacy as they can get in nuclear family.

People can't keep secrets hidden and as a result there is no privacy. There is no independent decision making in a joint family. People lose individuality.

This results in switching over to the nuclear family and there are positive aspects of a nuclear family due to which the quality of marital life of the youth will not get affected.

1) Privacy - The couple can get their privacy in their own house in nuclear families whereas you cannot get your privacy in a joint family. People can live their own way and can do whatever they want to. There are no such boundaries set by the elders to follow.

2) Financial stability - Financial stability is one of the strongest points in the nuclear family. One can be financially strong because of limited expenses. There is less number of people in the nuclear family and hence less expenses. People cannot have a strong financial stability if they are the only person who is earning in a joint family.

3) Freedom - The elders restricts youngsters not to do certain tasks because they think this is not good for them. But today's generation is very smart. They know what is good and bad for them and have enough analytical power so they don't like to restrict themselves. Instead, they want their freedom so that they can do and achieve whatever they want in their life.

(C) The International Journal of Indian Psychology, ISSN 2348-5396 (e)| ISSN: 2349-3429 (p) | 131 


\section{Change in Family Structure in the Modern Times}

4) Ease in moving - When people have a nuclear family, they face fewer problems while shifting from a house. They can manage their things according to them without disturbing the lives of other people. This is one of the major advantages of the nuclear family.

5) Avoidance of stress and discomfort - Some people are emotional. They can't tolerate any kind of fun that is on them and in the joint family, one need to have much high patience. But, nuclear families has the advantage that if people live in the company of those with whom they are very comfortable then there is no need to take any stress and their discomfort will also get vanished in a moment.

\section{Joint family system vs. Nuclear family system}

Today we have a generation of people who after having lived in a joint family system have taken the initiative to break out and start a nuclear family.

This generation today has come of age and very well appreciates the strengths and weaknesses of both the system. In a sense I represent such a generation and therefore wish to present my personal thoughts on why and how we could revive and make a 'the joint family system' work.

The generation that broke out of the old joint family system did so when individualistic thinking began to gain predominance in the society. It was exciting to explore experiment and establish a living set up on one's own.

The nuclear family gave immense freedom from the traditions and ways of life that the old system was ridden with.

Hence whenever and wherever the parents and the grown up adult children could not get along well and when the adult children could afford to build a house to call their own, nuclear families began to be formed. As it happens with most changes in the society, initially the people from the old system did not take this change very well. They were saddened to see the disintegration of family values and system and emergence of individualistic nuclear families.

However, gradually when nuclear families became the order of the day, the old generation slowly began to accept the realities and became comfortable with it.

The other factor that gave rise to nuclear families was industrialization. Industrial revolution brought with it increase in job opportunities in and around major industrialized and commercial cities and towns.

This forced men and women to move out of their family home and away from the parents. In this case, often the parents who remained emotionally attached to the place where they spent most of their life preferred to continue staying in their family home and accepted with some sadness their children starting out new life away from them. 


\section{Change in Family Structure in the Modern Times}

Today, as a person from the generation that broke out of the system in the hope of immense freedom, I look behind and ask myself 'what has my generation really and truly gained from the quest for freedom and what has it lost'.

The one and only major gain that I see from the 'nuclear family' system is the opportunity it provides us to create an identity of our own - something we as human beings crave for and are born for.

\section{On the loss side there are several}

Being physically far removed from the family members and as a result inadvertently getting disconnected from their hearts and minds, Stresses in bringing up our children only relying on child care centers. In Indian cities and towns, it can be even more difficult where there are not enough facilities available for care of children.

Coping with all problems - big and small on our own as we are unable to afford the privilege of sharing and downloading worries on someone (other than spouse) whom we feel close and connected to. This has led to increase in several problems in the society like depression, suicides and heart disorders due to highly stressed lives.

Missing out on celebrations and festivities that binds us to our culture and gives us a sense of being at home. This is more relevant to those living out of the country. Having difficulty in passing on the cultural values to our children. Cultural values are learnt and taught by seeing them in action. Facing great difficulty in even passing on our own language to the next generation. (This is more applicable for those who have moved out of the country.)

Through this article I wish to propose that based on our experiences of two fundamentally different models of family, we create a new family model based on the 'joint family system'.

In this new model the basic and underlying concept of the joint family would remain the same however it will incorporate changes in the ways members in the family interact with one another. The basic concept of the joint family system is that more than one family comes together under one roof and led a life of mutual co-operation and inter-dependence. In the revived model, the families coming together may or may not belong to the same parent family. A joint family system could be created by a family of friends.

\section{CONCLUSION}

Due to the western impact over contemporary Indian social system, tremendous changes affected every walk of life. 


\section{Change in Family Structure in the Modern Times}

These changes have influenced the society not only overtly but also have provided alternatives to the existing values and ideas towards the different aspect of society and human behavior.

But on the other hand, it is also equally true that Indian traditions are so deeply rooted that these alternatives have been succeeded in total transformation of the society. Culture is developed according to requirement of peoples of that region.

They have always meant for good and made for good but affects adversely, only when taken in a wrong way. Indian youth if understands the importance of western culture, it is for sure that it is going to affect his/her behavior, outlook and character in a smarter and better way.

We should adapt whatever can be adjusted with your culture and should modify the things, which can improve your culture.

The youth have enhanced our standard of living. I think if a country is growing by adapting western culture, you won't say it has adversely affected. Many concepts like keeping the environment neat and clean, strong offence for eve teasing and bullying, equality between man and woman \& boys and girls, appreciating the work of others, which have continuously been in their culture, if adopted by an Indian will going to widen our strengths.

All cultures are good until your culture is good and flexible, and you do it and adapt it in a positive way. So I think Indian youth has some positive as well as some negative effect of western culture on u and your family according to their thinking and beliefs.

\section{Following are conclusions on the basis of the research}

It is concluded that the Indian family structure has had a capacious impact on the contemporary Indian society.

The structure of Indian families is so orchestrated that it goes conjointly with the Indian social values and culture. Indian family structure is believed to be the unit that teaches the values and worth of an honest living that have been carried down across generations. Since the Puranic ages, Indian family structure was that of a joint family, indicating every person of the same clan living together.

From generations the Indian society has embraced and inculcated the traditional moral values of Indian families. Due to an expeditious change in the organization of Indian families there have also been changes in the contemporary society of India. According to the study, it has been found out that there is a significant difference between the values of children and parents both in joint and nuclear families. 


\section{Change in Family Structure in the Modern Times}

The parents of nuclear families have distinct perspective to raise their children and make them aware of the world around them, whereas parents in the joint families have traditional perspective to raise their own. Also children in nuclear and joint families see life from a different scope from each other which also leads to the difference in the development of the personality of each individual child.

Nonetheless, the bonding between the parents and the children in both nuclear and joint families have been of love, respect and care invariant of time. In the end it can be rightfully concluded that Indian family structure has been varied in varied periods of time and in different regions of the nation. The society structure and regulations have the highest influence on such formations of Indian family structures.

It is known through the findings that the youth nowadays have increasingly supported the idea of a nuclear family over joint family because of its various advantages and comfort. Moreover there has been a conscious need to maintain privacy and seclusion from the orthodox ideals of joint family. However there are certain aspects of joint family which fill the needs of a nuclear family. But through time and experience it is more preferred to be in a nuclear family than a joint family. Hence, the Youth is more inclined towards the idea of nuclear family rather than a joint family.

In the end we have come to a result that the western culture has had an immense impact on the Indian youth and hence the decisions and thinking has radically changed through time. From clothes, food and shelter Indian youth has now been considering different choices especially when it is related to the western culture, this is why now the decisions in any aspect of the life of Indian youth is more or less related to the western culture. Therefore, the Indian youth is decision of family planning in the Indian youth has been greatly influenced by the western culture.

According to the results of the investigation, the main reason for the increase in nuclear family and joint family has been a need for a financially independent, socially organized and self-reliant family. The change in thinking of the youth accumulated with impact of western culture has diversification of the families. As a result there has been a significant increase in the preference of a nuclear family than a joint family.

\section{KEY LEANINGS}

During my research I found that the family as a social institution has always been regarded as a core element types for the development of the individual as well as for the society and for the state.

Therefore the changes of family values are given much attention all over the world. As we have discussed about the development of an individual, society, and state which very much depends 


\section{Change in Family Structure in the Modern Times}

on the family. Hence this change requires the knowledge of this status quo condition and context of the change.

The function of the family is not any more natural than its concept but are changing and shifting in relation to social and economic developments. The family is the foundational institution in societies- an institution which is a site of identity, emotion, cultural expression, care, despair, reproductive labour, systemic, and systematic violence, repression, and domination in ways that other institutions are not. It is also foundational in that contestations over life and culture begin here.

In India its position has been central and critical. The family performs important task which contribute to society's basic needs and helps to perpetuate social order. Family is also described as "a group of persons directly linked by kin connections, the adult members of assume responsibility for caring for children".

The world of the family looks very different than it looks fifty years ago, while the institution of family and marriage still exist and are important to our lives, though the character has changed dramatically. Several sociologists have given their opinion about the family and its constituents.

Moreover, there have been many studies which shows that migration to cities has contributed to the rapid disintegration of large size family unit in village and town. In fact the observation based on family data show a high percentage of nuclear family in cities. With problem of finding accommodation and limited space available for living in cities, it become difficult for an average urbanite to maintain and support a large family. In industrial society the role of the family in stabilizing adult personalities is said to be critical. Other than these family structures there are few other of families are sustaining.

It can be seen now a days that the joint family structure is being nuclearised. It is not that joint less of the family in India is lost totally. It is just the "cutting off" point of joint less is changing. It is not quite possible that stage will come when the joint family will be lost from the mental horizon of the people of India.

As India is culturally established country, it has been seen that there is change in the culture of the living of the family. But it is still well established, instead of large joint family, now we have small joint family of two generations functioning effectively.

\section{Acknowledgments}

The author appreciates all those who participated in the study and helped to facilitate the research process. 


\section{Change in Family Structure in the Modern Times}

\section{Conflict of Interests}

The author declared no conflict of interests.

\section{REFERENCES}

Thomas, William; Florien Znaniecki (1996). The Polish Peasant in Europe and America: A Classic Work in Immigration History. Urbana: University of Illinois Press.

Van den Berghe, Pierre (1979). Human family systems: an evolutionary view. Elsevier North Holland, Inc.

Wrigley, E. Anthony (Spring 1997). "Reflections on the History of the Family.". The Family (The MIT Press.)

\section{Websites}

http://www.boloji.com/family/00117.htm

http://emeraldinsight.com/1747-3616.htm

http://www.helium.com/items/1060921-discussing-the-advantages-of-an-extended-family-

support-system

http://www.highbeam.com/doc/Common/Controls/

http://www.hinduismtoday.com/modules/smartsection/item.php?Itemid=4768

http://www.india-family

http://www.indianest.com/family/00117.htm

http://www.itwassoeasy.com/Author/4899/

http://www.newworldencyclopedia.org/feedback/extended_family

http://www.salagram.netjointfamily.htm\#

How to cite this article: H Bhasin (2016), Change In Family Structure In The Modern Times, International Journal of Indian Psychology, Volume 3, Issue 4, No. 66, ISSN 2348-5396 (e), ISSN: 2349-3429 (p), DIP:18.01.169/20160304, ISBN: 978-1-365-39396-9 